\title{
Preliminary report: Pedigree analysis of the Brangus cattle in South Africa
}

\author{
J.W. Steyn ${ }^{1,2 \#}$, F.W.C. Neser ${ }^{1}$, C. Hunlun ${ }^{3}$ \& P.C. Lubout ${ }^{2}$ \\ ${ }^{1}$ Department of Animal, Wildlife and Grassland Sciences, University of the Free State, P.O. Box 339, Bloemfontein \\ 9300, South Africa \\ ${ }^{2}$ Brangus Cattle Breeders Society of South Africa, P.O. Box 12465, Brandhof 9324, South Africa \\ ${ }^{3}$ SA Studbook and Animal Improvement Association, P.O. Box 270, Bloemfontein, 9300, South Africa
}

Copyright resides with the authors in terms of the Creative Commons Attribution 2.5 South African Licence.
See: http://creativecommons.org/licenses/by/2.5/za/
Condition of use: The user may copy, distribute, transmit and adapt the work, but must recognise the authors and the South African Journal
of Animal Science

\begin{abstract}
The aim of the study was to investigate some population parameters, including generation interval, inbreeding and effective population size of Brangus cattle in South Africa (SA) to assist in constructing an effective selection programme for the SA Brangus breed. Pedigree analysis can describe the genetic variability and change over time, making it an important tool to be used to assess parameters like generation interval, inbreeding, effective population size and number of animals selected against number born. These traits can be used to make more informed selection decisions in order to maintain a genetically healthy population through a better understanding of the dynamics within the population. A Population Structureand Pedigree Analysis Report was generated with the PopReport programme from the Institute of Farm Animal Genetics (FLI) with a Brangus datafile containing 65536 animals. Results were reported for the time period of 1986 to 2008 and the following results were obtained: 3-generation pedigree completeness is at 73.8\% for 2008, with an inbreeding coefficient of $1.39 \%$ and an annual increase in inbreeding of $0.058 \%$. Weighted generation interval was 5.17 years and the effective population size based on the average inbreeding was 166.7 animals.
\end{abstract}

Keywords: Pedigree analysis, Brangus, inbreeding

\#Corresponding author: hannesjws@gmail.com

\section{Introduction}

The Brangus is a composite breed, originally composed of 3/8's Brahman and 5/8's Angus. The first Brangus animal was imported into SA in 1963. In addition to several imports of pure Brangus cattle from the United States of America (USA), breeders in SA have been crossbreeding Brahman and Angus cattle to breed Brangus animals. The breed has an open studbook policy which allows Brangus-type animals to be inspected and registered as Appendix A or B animals if they comply with the breed standards. Brangus semen and embryos have also been imported on a regular basis since the establishment of the South African Brangus Cattle Breeders Society (SABCBS). This allows for a consistent introduction of new genetic material into the local population, increasing genetic variability. However, the continuous use of specific popular AI bulls could lead to increased levels of relationships within the breed, inbreeding and decreased genetic variability. Effective selection programmes are based on the knowledge of the available genetic variability in a population (Gutiérrez et al., 2003). No previous study has been done on the genetic variability and genetic status of the SA Brangus breed. It was therefore decided to do a pedigree analysis to estimate population parameters for the breed. Information on the genetic interval, inbreeding coefficient and effective population size of a breed could be used to make informed selection decisions to maintain a genetically sound population through a better understanding of the dynamics within the population.

Generation interval is defined as the average age of parents when their selected offspring are born (Bourdan, 2000). This is one of the parameters that influence genetic change, as a shorter generation interval result in faster genetic change. An animal is considered selected if it has produced at least one progeny itself 
(Groeneveld et al., 2009). Inbreeding is defined as the probability that two alleles located on the same locus, are identical by descent (Bourdan, 2000). In other words, it is the probability that the same gene was inherited from an ancestor through both the dam and sire. The inbreeding coefficient (F) quantifies this probability as a fraction between 0 and 1 , while the rate of inbreeding $(\Delta \mathrm{F})$ reflects the change in inbreeding per generation. Pedigree completeness, which is expressed as the percentage of animals with completed pedigrees per generation, is important to estimate inbreeding. This factor could be an important factor why inbreeding differs between breeds. It should be obvious that population parameters based on more complete pedigrees offer more reliable information. Effective population size $\left(\mathrm{N}_{\mathrm{e}}\right)$ is the size of an idealised population that would give rise to the same rate of inbreeding that is observed in the population under investigation (Gutiérrez et al., 2003). $\mathrm{N}_{\mathrm{e}}$ can be based on either the rate of inbreeding, or on the number of parents that produced progeny in the population. $\mathrm{N}_{\mathrm{e}}$ based on the number of parents can give large overestimates of the real effective population size and do not take the relationship between parents into account. $\mathrm{N}_{\mathrm{e}}$ based on the number of parents should only be used within the same population over time, in which case it can give an indication of the relative changes that may occur in the available genetic diversity in the population.

The aim of this study was to investigate some population parameters such as the generation interval, inbreeding and effective population size for Brangus cattle in South Africa in order to assist in constructing an effective selection programme for the breed.

\section{Materials and Methods}

The data file used for this study was obtained from the 2010 Breedplan/Brangus BLUP run and contained 65536 animals born from 1953 to 2010. The reference year was 1986, when the SABCBS was established. Results were reported up to 2008, as the data for 2009 and 2010 was incomplete at the time. A Population Structure- and Pedigree Analysis Report was generated with the PopReport program from the Institute of Farm Animal Genetics (FLI) in Germany (Groeneveld et al., 2009). The relative change in average inbreeding $(\Delta \mathrm{F})$ was obtained by linear regression of the average annual inbreeding coefficient $(\mathrm{F})$ over years. By including the number of animals involved in obtaining each annual generation interval when calculating the overall average generation interval, a weighted generation interval was calculated. Effective population size based on the number of parents was calculated by PopReport with the formula $\mathrm{N}_{\mathrm{e}}=\left(4 \mathrm{~N}_{\mathrm{m}} \mathrm{N}_{\mathrm{f}}\right) /\left(\mathrm{N}_{\mathrm{m}}+\mathrm{N}_{\mathrm{f}}\right)$, where $\mathrm{N}_{\mathrm{f}}$ and $\mathrm{N}_{\mathrm{m}}$ represents number of dams and sires respectively (Groeneveld et al., 2009). Effective population size $\left(\mathrm{N}_{\mathrm{e}}\right)$ based on the rate of inbreeding was obtained with the formula $\mathrm{N}_{\mathrm{e}}=1 /\left(2^{*} \Delta \mathrm{F}\right.$ ) (Groeneveld et al., 2009) using the $\Delta \mathrm{F}$ as calculated above after adjusting the base of calculation to a per generation base using the calculated average generation interval.

\section{Results and Discussion}

Pedigree information became more complete over the 23 year time period, with the three generation pedigrees increasing from $28.7 \%$ in 1986 to $73.8 \%$ in 2008. The trend in the number of complete pedigrees over the last five years of the study seems to be slightly downward, as the 3-generation complete pedigrees peaked at $78.3 \%$ in 2004 . This is possibly due to more animals without any or incomplete pedigree information being inspected and added as appendix animals. Although Kluyts (1993) mentioned that the pedigree information on the Brahman breed in South Africa is relatively incomplete, no specific pedigree completeness levels is provided. Only complete 4-generation pedigrees were used in the studies on the Drakensberger breed (Dreyer, 1982) and the Brahman breed (Kluyts, 1993). Van der Westhuizen (2009) reported 85\% pedigree completeness for 3-generation pedigrees in the Bonsmara breed between 2000 and 2007. This is higher than the 73.9\% found in the Brangus breed during the same period. There does not seem to be a specified level of pedigree completeness recommended in the literature to make conclusive decisions about inbreeding or other population parameters.

The regression function of average inbreeding coefficient on year of birth was calculated as:

$$
y=0.00058 * x-1.142\left(R^{2}=0.957\right)
$$

This translates into an increase in inbreeding $(\Delta \mathrm{F})$ of $0.058 \%$ per year. This is higher than the increase in inbreeding for the Brahman at $0.006 \%$ reported by Pico et al. (2006), but it is still considered as being low.

The number of animals born per year has increased steadily over the 23 years of the study (Figure 1). The number of animals selected annually has also increased, but not at the same rate. The trend in the 
generation interval seems to be decreasing, which will result in faster genetic change in selection programmes. The effective population size based on the number of parents shows that the population has steadily grown in the time period considered.

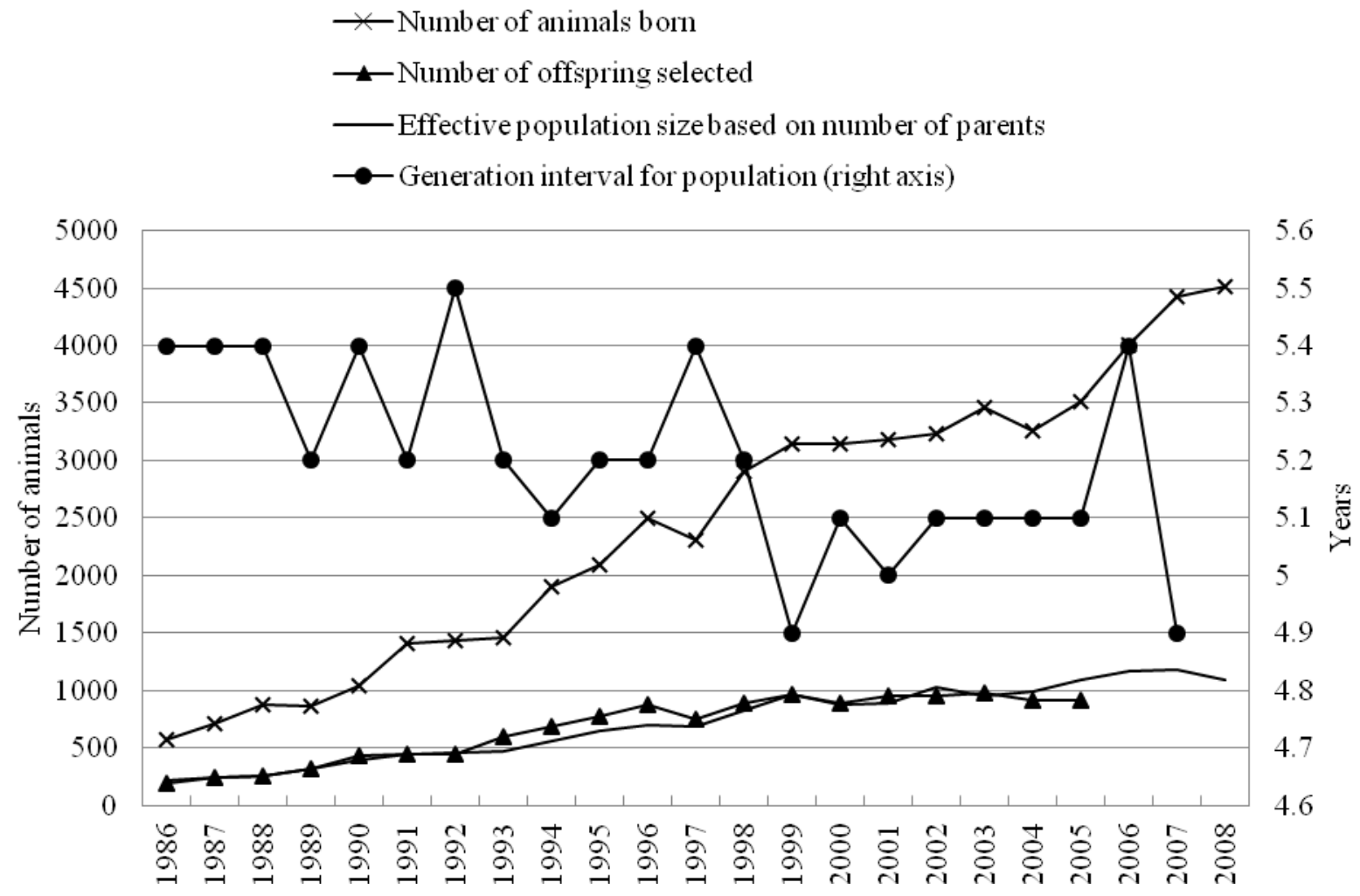

Figure 1 The total number of animals born and selected to stay in the breeding population, as well as generation interval and effective population size as affected by year of birth.

The average inbreeding coefficient in the Drakensberger breed in 1976 was 5.73\% (Dreyer, 1982). Kluyts (1993) reported an inbreeding coefficient of 1.28\% in the Brahman breed in 1982, while (Pico et al., 2006) later reported an inbreeding coefficient of $1.31 \%$ for Brahman animals born in 2002. For the Bonsmara breed, an average inbreeding coefficient of 1.85\% was reported for animals born in 1998 (Mostert \& Exley, 2000), which was confirmed by Van der Westhuizen (2009) at 1.8\% in 2006. This means that, compared to some other South African beef cattle breeds, the inbreeding coefficient as observed in the present study of $1.39 \%$ found for animals born in 2008 in the Brangus breed, is relatively low.

The effective population size based on the regression of the average inbreeding coefficient was found to be 167 animals. The weighted generation interval for the SA Brangus was calculated as 5.17 years, which compares well to the 5.6 years in the Bonsmara breed as found by Hunlun (2010). Figure 2 shows a steep increase in the number of inbred animals from 6 to 2380, but at the same time the average inbreeding coefficient of the inbred animals has decreased. An inbreeding coefficient of $6.25 \%$ and above is generally accepted as being significantly inbred and inbreeding depression will start to negatively influence such an animal. Figure 2 also shows that the average inbreeding coefficient for the breed as a whole is increasing, while the regression line shows an increase of $0.058 \%$ per annum in the average inbreeding coefficients for the population over the 23 years.

\section{Conclusion}

From 1986 to 2008, the number of animals in the SA Brangus breed has increased. However, the level of inbreeding in the breed is low and comparable to other South African beef breeds. While the number of inbred animals has increased, the inbreeding coefficient for inbred animals declined at the same time. The generation interval seems to be decreasing for the time period reported and is comparable to other beef 


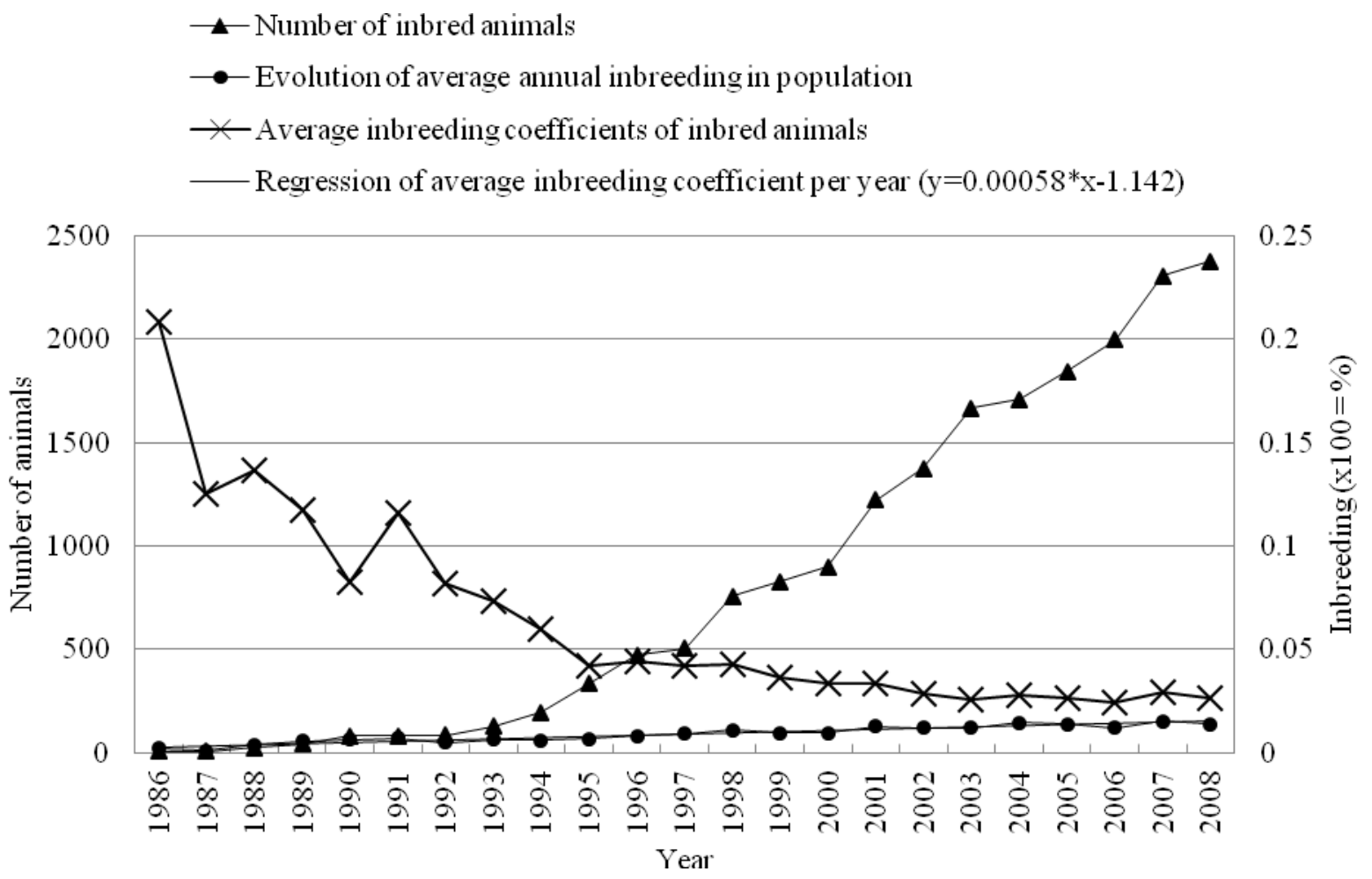

Figure 2 Evolution of inbreeding in the population and inbred animals, number of inbred animals and inbreeding coefficient as affected by year of birth.

breeds. As neither the level of inbreeding nor the rate of increase in inbreeding are at levels causing concern, current breeding practices should continue, with constant monitoring of the population parameters. Generation interval should be maintained at a level as low as possible under practical farming conditions. The growth in numbers in the breed provides opportunity for stricter selection. However, breeders should strive to continue to record more complete pedigrees, which will make future genetic analyses more accurate.

\section{References}

Bourdan, R.M., 2000. Understanding Animal Breeding. 2 ed. Prentice Hall, New Jersey.

Dreyer, C.J., 1982. Die teeltstruktuur van die Drakensbergerbeesras en faktore wat die doeltreffendheid van produksie beïnvloed. D.Sc. (Agric)-verhandeling, University of Pretoria, Pretoria. (In Afrikaans).

Groeneveld, E., Van der Westhuizen, B., Maiwashe, A., Voordewind, F. \& Ferraz, J.B.S., 2009. POPREP: A generic report for population management. Genet. Mol. Res. 8, 1158-1178.

Gutiérrez, J.P., Altarriba, J., Díaz, C., Quintanilla, R., CaNón, A. \& Piedrafita, J., 2003. Pedigree analysis of eight Spanish beef cattle breeds. Genet. Sel. Evol. 35, 43-63.

Hunlun, C., 2010. Adding value to data emanating from routine animal recording processes. Proc. ICAR $37^{\text {th }}$ Annual meeting. Riga, Latvia, 189-198.

Kluyts, J.F., 1993. Die teeltstruktuur en genetiese analise van die Brahmanras met klem op moontlikhede vir genetiese verbetering. M.Sc. (Agric)-verhandeling, University of Pretoria, Pretoria. (In Afrikaans).

Mostert, B.E. \& Exley, C.A.J., 2000. Inbreeding of the Bonsmara cattle breed. S.Afr.J. Anim. Sci. 30, 89-90.

Pico, B.A., Van Wyk, J.B. \& Neser, F.W.C., 2006. Inbreeding in the South African Brahman breed. S. Afr. J. Anim. Sci. 36, 103-106.

Van der Westhuizen, B., 2009. Population history and genetic variability in Bonsmara beef cattle via a pedigree analysis. In: Bonsmara: Born to breed - born to lead. Eds Ferreira, P. \& Webb, E., Bonsmara SA. Bloemfontein, 2009. pp. 258-268. 